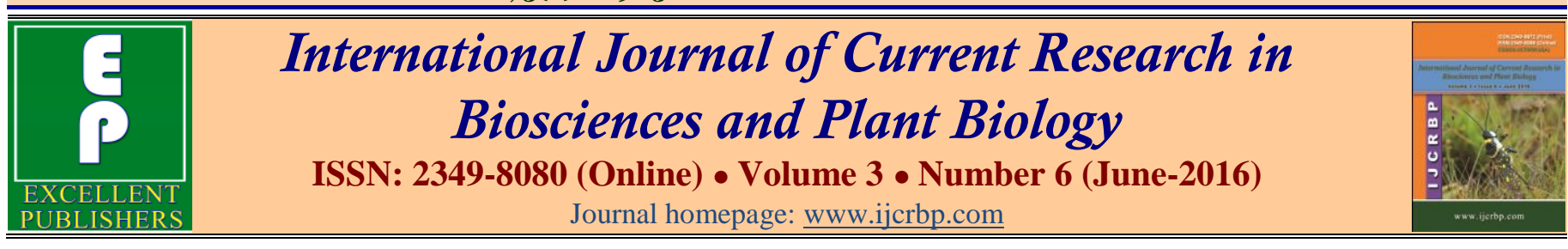

\title{
Nutrition Care Process and Chronic Kidney Disease: A Review
}

\author{
Sanjeev Kumar Mishra ${ }^{1,2 *}$, Karuna Singh $^{3}$ and Rajul Kumar Gupta ${ }^{4}$
}

${ }^{1}$ Joint Director (Med \& Health), Integrated HQ of MoD (Army), DGIS, DGIS Enclave, Rao Tula Ram Marg, Near Shankar Vihar, New Delhi - 110 o10, India

${ }^{2}$ Ph.D. Scholar, Amity Institute of Food Technology, Amity University, Sector 125, Noida - 201 303, UP, India

3 Amity Institute of Food Technology, Amity University, Sector 125, Noida - 201 303, UP, India

${ }_{4}^{4}$ Director Armed Forces Medical Services (Health), DG3A, Room NO 4A, M Block, O/o DGAFMS, Church Road, New Delhi -

110001, India

*Corresponding author.

\begin{abstract}
The nutrition care process (NCP) is a four-step approach to nutrition problem solving and care that is designed to guide and illuminate the work of the professionals. NCP model provides a consistent structure and framework for food and nutrition professionals to use while delivering nutrition care. A standardized language in form of International Dietetic and Nutrition Terminology (IDNT) has been in place to communicate, document and evaluate the efficacy of nutrition care and may translate into improved clinical outcomes. Implementation of the NCP helps to generate comparative data and information relating to the impact of nutrition interventions to resolve nutrition problems. Malnutrition is one of the important features of chronic kidney disease (CKD) and it occurs in varying degrees depending on stage of CKD. Various studies have supported the implementation of a systematic approach to patient care in line with NCP and have shown improvement in dietary intake and nutritional status among CKD patients. Providing individualised nutritional counselling improves many components of quality of life prior to dialysis treatment. The overall goal of implementing NCP among CKD patients is to match dietary intake with existing kidney function or renal replacement therapy while preventing nutritional deficiencies. Literature published between January 1985 and January 2016 in peer reviewed scientific journals were considered. Only full text articles in English were included. This review article attempts to highlight the important features of Nutrition Care Process (NCP) and International Dietetics and Nutrition Terminology (IDNT) and its potential application in chronic kidney disease (CKD).
\end{abstract}

\section{Introduction}

The constant evolution of the healthcare environment worldwide is not only creating more complex medical care with improved outcomes, but also expecting increased efficiency of all actors within the health care system (Donaldson et al., 2004). In order to meet the expectations, it is crucial to provide care according to best practice and

\section{Article Info}

Accepted: 27 May 2016

Available Online: 06 June 2016

\section{Keywords}

Chronic kidney disease Dietetic and nutrition

Nutrition care process 
to describe diagnosis and treatment for those within and outside the medical profession. Examples of controlled vocabularies familiar to dieticians include the Common Procedure Terminology (CPT) and the International Classification of Diseases (ICD) terminologies developed for use by physicians. The establishment and implementation of a standardized Nutrition Care Process (NCP) and Model were identified as priority actions for the profession for meeting goals of the American Dietetic Association (ADA) Strategic Plan to "Increase demand and utilization of services provided by members and empower members to compete successfully in a rapidly changing environment" (Lacey et al., 2003).

Providing high-quality nutrition care means doing the right thing at the right time, in the right way, for the right person and achieving the best possible results. Quality improvement literature shows that, when a standardized process is implemented, less variation and more predictability in terms of outcomes occur. When providers of care, no matter their location, use a process consistently, comparable outcomes data can be generated to demonstrate value. A standardized Nutrition Care Process effectively promotes the dietetics professional as the unique provider of nutrition care when it is consistently used as a systematic method to think critically and make decisions to provide safe and effective nutrition care (Shojania et al., 2001).

Chronic kidney disease (CKD) has become major public health problem worldwide. Malnutrition is an important feature of CKD. Malnutrition occurs in varying degrees depending on the stages of CKD (Kopple et al., 1989). Malnutrition is seen in patients on haemodialysis (Hakim and Levin, 1993) as well as in those on peritoneal dialysis (Fein et al., 2003). Many studies have shown that malnutrition is associated with increased mortality (Marcen et al., 1997). Protein energy malnutrition is usually an important component of Protein Energy Wasting (PEW) (Fouque et al., 2008). When CKD reaches stages 4 and 5, a decline in protein and energy intakes is often accompanied by worsening protein energy status (Kopple et al., 2000). Nutritional and metabolic derangements are common in CKD and play a major role in affecting clinical outcome in patients (Kopple, 1994). The NCP is a necessary tool for assessing and monitoring nutritional status in the current clinical practice (Ruperto, 2014).

This review article attempts to highlight the important features of Nutrition Care Process (NCP) and International Dietetics and Nutrition Terminology
(IDNT) and its potential application and implementation in chronic kidney disease.

\section{Nutrition Care Process and Model (NCPM)}

Nutrition Care Process is defined as "a systematic problem-solving method that dietetics professionals use to critically think and make decisions to address nutrition related problems and provide safe and effective quality nutrition care" (Lacey et al., 2003). The NCPM provides a consistent structure and framework for food and nutrition professionals to use when delivering nutrition care and is designed for use with patients, clients, groups and communities of all ages in conditions of health or disease (Myers, 2008).

\section{Nutrition Care Model}

The Nutrition Care Model is a visual representation that reflects key concepts of each step of the Nutrition Care Process and illustrates the greater context within which the Nutrition Care Process is conducted (Lacey et al., 2003). An illustration of the model is described below in Fig. 1. The model comprises of:

(a) Central core: Relationship between patient / client / group and dietetics professional.

(b) Inner ring: Four steps of the nutrition care process are in the inner ring.

(c) Middle ring: Strengths and abilities that dietetics professionals bring to the process (dietetics knowledge, skills, and competencies; critical thinking, collaboration and communication; evidence-based practice, and Code of Ethics) (Gates, 2003). The middle ring identifies abilities of dietetics professionals that are applicable to the Nutrition Care Process. These include the unique dietetics knowledge, skill and competencies that dietetics professionals bring to the process, in addition to a welldeveloped capability for critical thinking, collaboration, and communication (Lacey et al., 2003).

(d) Outer ring: The outer ring identifies some of the environmental factors such as practice settings, health care systems, social systems and economics which impact the ability of the patient/ client/group to receive and benefit from the interventions nutrition care. It is essential that dietetics professionals assess these factors and be able to evaluate the degree to which they may be either a positive or negative influence on the outcomes of care (Lacey et al., 2003). 


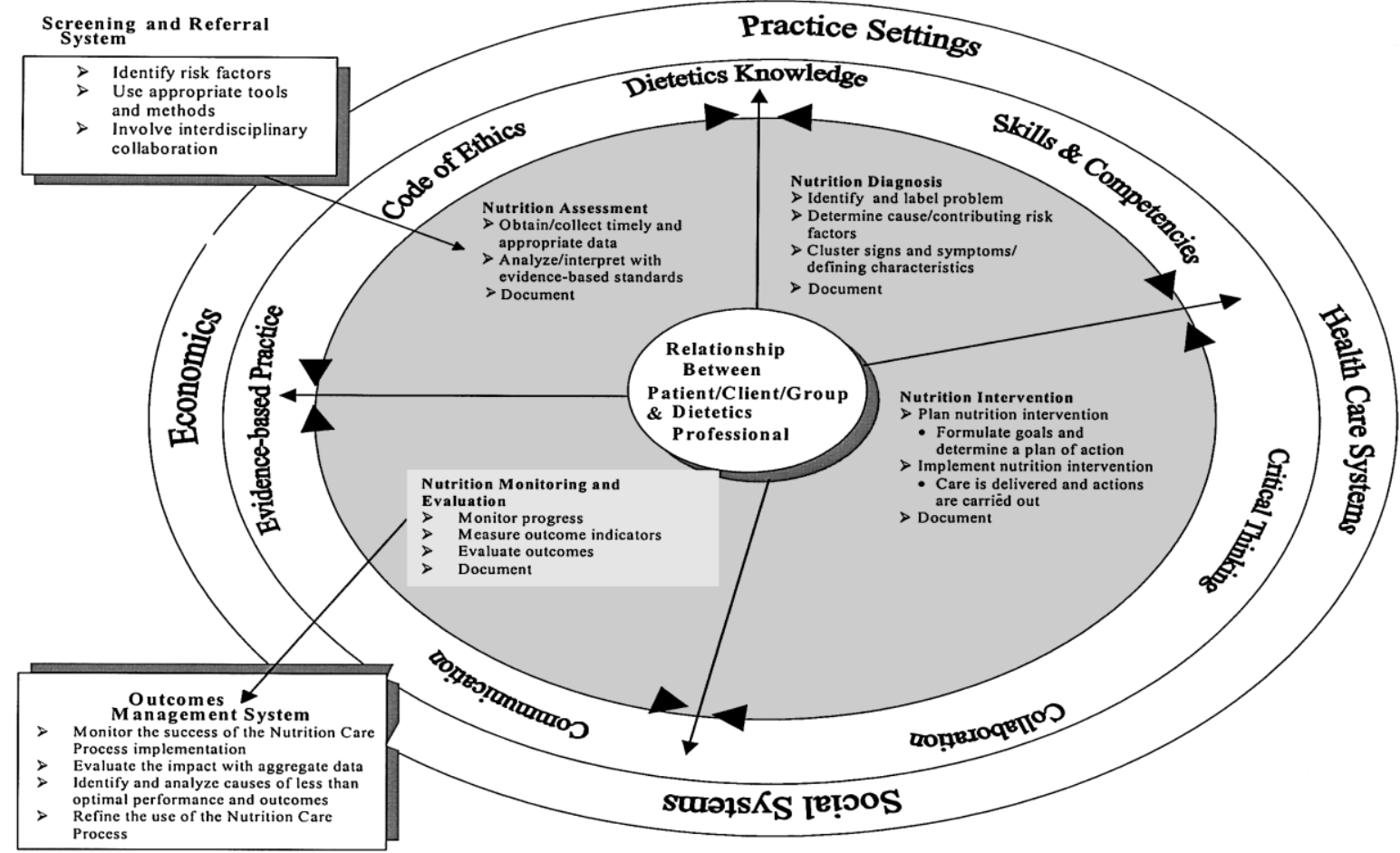

Fig. 1: The four distinct but interrelated and connected steps of the Nutrition Care Process and Model.

\section{e) Supporting systems:}

(i) Screening and referral system as access to nutrition care: Nutrition screening is a supportive system and not a step within the Nutrition Care Process (NCP). Screening is an identification step that is outside the actual "care" and provides access to the NCP. The NCP depends on an effective screening and/or referral process that identifies clients who would benefit from nutrition care (Houston et al., 1998).

(ii) Outcomes management system: An outcomes management system evaluates the effectiveness and efficiency of the entire NCP. Because outcomes management is a system's commitment to effective and efficient care, it is depicted outside of the NCP. Outcomes management links care processes and resource utilization with outcomes (Lacey et al., 2003).

\section{Components of NCP}

The NCP consists of four distinct but interrelated and connected steps (Lacey et al., 2003). They are:

(a) Nutrition assessment

(b) Nutrition diagnosis

(c) Nutrition intervention

(d) Nutrition monitoring and evaluation

\section{Nutrition assessment}

Nutrition assessment is the first step in the process and is a method for obtaining, verifying, and interpreting data that is needed to identify a nutrition-related problem. From the nutrition assessment data, the practitioner is able to determine whether a nutrition diagnosis/problem exists. This step is used throughout each cycle of the nutrition care process and is a dynamic process that develops throughout the nutrition care process. For example, a dietetics practitioner may be in the middle of the nutrition education intervention when the client provides a new piece of information that may cause a modification of the nutrition diagnosis, PES statement, or even the nutrition intervention (Lacey et al., 2003).

\section{Nutrition diagnosis}

Nutrition diagnosis is the critical link in the nutrition care process between nutrition assessment and nutrition intervention. The purpose of a standardized nutrition diagnosis language is to consistently describe nutrition problems so that they are clear within and outside the profession. Nutrition interventions can then be clearly targeted to address either the aetiology or signs and symptoms of the specific nutrition diagnosis identified (Lacey et al., 2003). Using a standardized terminology for identifying the nutrition diagnosis will provide a clear 
method of communicating among dietetics professionals (Underbakke, 2006).

The 62 nutrition diagnoses have been given labels that are clustered into three domains: intake, clinical and behavioural-environmental. Each domain represents unique characteristics that contribute to nutritional health. Within each domain are classes and subclasses of nutrition diagnoses.

The Intake domain lists actual problems related to intake of energy, nutrients, fluids, or bioactive substances through oral diet, or nutrition support (enteral or parenteral nutrition).

The Clinical domain is nutritional findings identified as related to medical or physical conditions.

The Behavioural-Environmental domain includes nutritional findings identified that relate to knowledge, attitudes/beliefs, physical environment, access to food and food safety (ADA, 2007).

The nutrition diagnosis is summarized into a structured sentence named as nutrition diagnosis statement or PES. PES statement is composed of three distinct components: the problem $(\mathrm{P})$, the aetiology $(\mathrm{E})$ and the signs and symptoms (S). The practitioner obtains the aetiology and the signs and symptoms during the nutrition assessment phase of the nutrition care process. The nutrition diagnosis is derived from the synthesis of nutrition assessment data, and the wording is obtained from the nutrition diagnoses reference sheets. The generic format for the nutrition diagnosis statement is: Problem (P) related to aetiology (E) as evidenced by signs and symptoms (S) (Lacey et al., 2003).

\section{Nutrition intervention}

Nutrition intervention is defined as purposefully planned actions designed with the intent of changing a nutritionrelated behaviour, risk factor, environmental condition, or aspect of health status for an individual, target group or the community at large (Lacey et al., 2003). A dietetics professional works in conjunction with patients, other health care providers or agencies during the nutrition intervention phase (ADA, 2007).

\section{Nutrition monitoring and evaluation}

Monitoring specifically refers to the review and measurement of the patients' status at a scheduled follow-up point with regard to the nutrition diagnosis, intervention goals and outcomes, whereas Evaluation is the systematic comparison of current findings with previous status, intervention goals, or a reference standard. Monitoring and evaluation use selected outcome indicators that are relevant to the patient's defined needs, nutrition diagnosis and goals. The purpose of monitoring and evaluation is to determine the degree to which progress is being made and goals or desired outcomes of nutrition care are being met. Data from this step are used to create an outcomes management system (Lacey et al., 2003).

The four steps of NCP were finalized based on extensive review and evaluation of previous works describing nutrition care (Doenges and Moorhouse, 2012; Splett and Mayers, 2001; Lacey et al., 2002; Sandrick, 2002). Even though each step builds on the previous one, the process is not linear. The Nutrition Care Process cycles through the steps of assessment, diagnosis, intervention, and monitoring and evaluation. Nutrition care can involve one or more cycles and ends, ideally, when nutrition goals have been achieved (Lacey et al., 2003).

\section{International Dietetics and Nutrition Terminology (IDNT)}

Activities of dietetic professionals within the four steps of the Nutrition Care Process are described using the International Dietetics and Nutrition Terminology (IDNT) (ADA, 2011). The IDNT was conceived as a controlled vocabulary, defined by the National Library of Medicine as a system of terms, involving definitions, hierarchical structure and cross-references, used to index and retrieve a body of literature in a bibliographic, factual, or other database. Dieticians are familiar with standardized languages such as the International Classification of Diseases (ICD-10) and the Common Procedural Terms (CPT) that are used extensively in health systems management. The nursing, physical therapy, and occupational therapy professions have created controlled vocabularies or standardized languages that describe their unique functions (Carpenito, 2005; Ma et al., 2007). Some of these vocabularies contain nutrition terms, but none of the terms adequately describe the breadth and depth of activities unique to the profession of dietetics (Myers, 2008). The standardized terminology is an important component of the NCP, to ensure that the terms used by different dieticians have the same meaning, regardless of the situation or the setting (Charney, 2006). The Academy of Dietetics and Nutrition hosted an 
international conference in 2010 with representatives from dietetics associations from seven countries to promote the usage of IDNT (Atkins et al., 2010; Ibrahim, 2010). Since then, many national dietetic associations have adopted the use of IDNT (Charney, 2006) and in 2011 the International Confederation of Dietetics Associations, ICDA, officially stated their support of the use of the NCP and related IDNT by dieticians all over the world.

\section{The electronic Nutrition Care Process Terminology (eNCPT)}

The Academy of Dietetics and Nutrition published the 2014 edition of the International Dietetics and Nutrition Terminology (IDNT) Reference Manual called as eNCPT. The online IDNT has been re-launched as the eNCPT. The electronic Nutrition Care Process Terminology features updated terminology, an improved web platform with easier manoeuvrability, language tabs for international translations, and for electronic health recording (EHR) builders, the 2014 NCPT spreadsheet of terms and abbreviations.

A standardized language aids in enhancing communication within and between health care disciplines. Standardized language terminology, particularly diagnostic codes, are essential in health care for communicating treatment plans and evidence-based practice (Myers, 2008; O'malley et al., 2005). Integration of the NCPM and IDNT into computerized medical record systems is beneficial for tracking and monitoring data sets measuring health outcomes as a result of nutrition care (Myers, 2008).

\section{Chronic Kidney Disease (CKD) and nutrition}

CKD is an emerging chronic disease globally (Ruggenenti et al., 2001). One reason is the rapidly increasing worldwide incidence of diabetes (Wild et al., 2004) and hypertension (Anand, 2000; Gupta, 2004). In the USA, data on epidemiology of CKD are made available through National Health and Nutrition Examination Survey (NHANES) and periodically updated. The NHANES is a cross-sectional survey sampled to be representative of the overall US population (Coresh et al., 2007). The available estimate of a CKD prevalence of $13 \%$ in the spans 1988-2004, includes 28,721 individuals over 20 years of age, and defines $\mathrm{CKD}$ as persistent albuminuria $>30 \mathrm{mg} / \mathrm{g}$ and/or estimated glomerular filtration rate (eGFR) below 60 $\mathrm{ml} / \mathrm{min} / 1.73 \mathrm{~m}^{2}$ by the Modification Diet in Renal
Disease (MDRD) formula. With increasing life expectancy and prevalence of life style diseases, US has seen a 30\% increase in prevalence of chronic kidney disease (CKD) in the last decade (Coresh et al., 2007). Another population-based, nationally representative survey from Taiwan detected $7 \%$ prevalence for individuals with eGFR below $60 \mathrm{ml} / \mathrm{min} / 1.73 \mathrm{~m}^{2}$ (Hsu et al., 2006). Studies from the UK (Stevens et al., 2007), Japan (Imai et al., 2007) and Australia (Chadban et al., 2003) confirm similar or higher prevalence.

Earlier it is considered to be a health problem only in developed countries, 4 out of 5 chronic disease deaths now occur in low- and middle-income countries (WHO, 2012). As per limited data available from India on prevalence of CKD in India, given its population $>1$ billion, the rising incidence of CKD is likely to pose major problems for both healthcare and the economy in future years. Indeed, it has been recently estimated that the age-adjusted incidence rate of ESRD in India to be 229 per million population (pmp) (Modi and Jha, 2006) and >100,000 new patients enter renal replacement programs annually in India (Kher, 2002). In a recently published Screening and Early Evaluation of Kidney Disease study (Singh et al., 2013), where the mean age of the population was $45.22 \pm 15.2$ years, the prevalence of CKD was found as $17.2 \%$ with stage 1 , $2,3,4,5$ as $7 \%, 4.3 \%, 4.3 \%, 0.8 \%$ and $0.8 \%$ respectively. $43.1 \%$ of their cohort had hypertension, and $18.8 \%$ had diabetes.

Malnutrition is an important feature of CKD. Various epidemiological studies have reported between 30 and $50 \%$ of patients with signs of malnutrition (Chauveau et al., 2001; Pifer et al., 2002; Kobayashi et al., 2010). Malnutrition is seen in patients on haemodialysis (Hakim and Levin, 1993) as well as in those on peritoneal dialysis (Fein et al., 2003). Many studies have shown that malnutrition is associated with increased mortality (Marcen et al., 1997). Malnutrition also negatively impacts on patients' outcome by accelerating atherosclerosis and by increasing susceptibility to infections (Yilmaz et al., 2007; Akdag et al., 2008; Zyga et al., 2011). Epidemiological studies repeatedly and consistently have shown a strong association between clinical outcome and measures of malnutrition (Fung et al., 2002; Kalantar et al., 2003).

In CKD, nutrition and diet play an important role both in prevention of disease progression and in symptom management (Ash et al., 2014). Since patients with CKD present an increased catabolic and inflammatory state 
with loss of proteins from muscles and other tissues, presenting a high risk of developing malnutrition and atherosclerosis and a high risk for $\mathrm{CV}$ morbidity and mortality from the early stages of the disease. In this light, a tailored nutritional intervention could represent a reliable strategy to reduce these risks (Caglar et al., 2002; Ikizler, 2004; Ikizler et al., 2013). The main pathophysiological rationale for nutritional intervention in CKD is to prevent the onset and to reduce the worsening of metabolic derangements and to possible modify the cardio-renal risk factors associated with CKD (Goraya and Wesson, 2012).

Several studies have shown that regular pre-dialysis attendance helps to provide the patient with proper education and thereby achieve better QOL (Quality of Life) (White et al., 2002). These findings were supported by the study conducted by Lii et al. (2007) who concluded that patients receiving psychosocial intervention showed reduced depression and better QOL compared with the control group. The implementation of a systematic approach to patient care, in line with nutrition management guideline recommendations, was associated with an improvement in nutritional status and dietary intake in this cohort of maintenance haemodialysis patients, without the need for increased resources or dietician time (Campbell et al., 2009). Quality of life is related to nutritional status in predialysis patients. Providing individualised nutritional counselling improves many components of quality of life, compared with standard nutrition care, in the stage prior to dialysis treatment (Campbell et al., 2008).

\section{Implementation of NCP}

Implementing NCP provides a framework to improves outcomes by (a) enhancing the health of individuals and groups; (b) potentially reducing health care costs by decreasing the need for medications, clinic and hospital visits; and (c) serving as the basis for research, documenting the impact of nutrition care provided by dietetics professionals (Bisognamo, 2000; Smith, 2003).

The NCP is designed to incorporate a scientific base that moves food and nutrition professionals to a higher level of evidence based practice. Using NCP has many advantages like (i) it provide professionals consistent and systematic structure and method to think critically and make decisions (Lacey et al., 2003) ; (ii) it assists professionals to scientifically and holistically manage nutrition care to meet their health and nutrition goals; (iii) it improves health outcomes by the dietetic professionals as the preferred providers of nutrition services (Myers, 2008); and (iv) when used consistently, it helps professionals to move beyond experience-based practice to reach a higher level of evidence based practice (Splett, 2000). (v) The Nutrition Care Process will be invaluable as research is completed to evaluate the services provided by dietetics professionals (Manore and Mayers, 2003).

\section{Application of NCP in CKD}

The NCP is designed to be used for individual patients as well as groups and populations. The specific goal of the subsequent NCP steps in patients with CKD stages 3 to 4/G3 to G4 is to reduce metabolic by products from dietary intake to stop or slow progression to kidney failure. The overall goal is to match dietary intake with existing kidney function or renal replacement therapy while preventing nutrition deficiencies (Brommage et al., 2009; Memmer, 2013). The four-step approach of NCP and the standardized language can be applied in CKD in the following ways:-

\section{(i) Nutrition assessment}

The nutrition assessment stage of the NCP in CKD is similar to the core standards of practice parameters (Beto et al., 2014). The patient needs to be evaluated for basic knowledge, health literacy, motivation factors, and barriers to change. The dietician collects general information on food intake, food preferences, and compliance levels. Establishing a baseline nutrition assessment as defined in the NCP is important when monitoring patients over time (Brommage et al., 2009; Holli, 2012). Basic dietary intake information can be obtained by a variety of methods, such as diet recalls or food records (Brommage et al., 2009; Holli, 2012). A more interactive and creative assessment method is to ask the patient to create a lifestyle timeline by taking a photographic cell phone picture each time a snack, meal, or food item is ingested for 1 day before the next scheduled visit (Beto et al., 2014). The visual interactive teaching format often provides important data and promotes general conversation. This strategy might also provide a more accurate objective estimation of intake, particularly when using computerized diet analysis to evaluate intake for protein sources and renal-specific nutrients (i.e., sodium, potassium, and phosphorus) (Beto et al., 2014).

For information regarding physical examination and laboratory findings a dietician should use the data 
provided in the medical record to aid in initial physical assessment. A measured height and body weight, rather than self-reported, should be performed to ensure accuracy. A dietician is not expected to perform an advanced nutrition-focused physical examination, but could use subjective global assessment (Brommage et al., 2009). Key changes in laboratory values should be noted for serum albumin, haemoglobin, creatinine, and blood urea nitrogen. Glycaemic and blood pressure control should be individualized and monitored per recommended guidelines for non-CKD patients. Appropriate NCP nutrition assessment information should be documented and shared with the interdisciplinary team (Brommage et al., 2009).

\section{(ii) Nutrition diagnosis}

Nutrition diagnoses are formulated using criticalthinking and problem-solving skills applied to NCP assessment data. For example, a nutrition diagnosis term (NI-5.7.2) of excessive protein intake could be linked to the objective findings of an elevated serum creatinine or blood urea nitrogen serum level. Selected common diagnoses might include excessive or inadequate dietary intake (e.g., protein, sodium, potassium, phosphorus), body composition changes (e.g., weight loss, muscle mass change), or behavioural /compliance status (e.g. knowledge deficit, motivation, or lifestyle issues) (Holli, 2012). One or more focused PES statements will be the result of this stepwise process. The conclusion of the assessment and diagnosis NCP steps will create a nutrition prescription that summarizes the next intervention, monitoring, and evaluation steps (Brommage et al., 2009).

\section{(iii) Nutrition intervention}

Nutrition interventions are tailored to eliminate, improve, or decrease the nutrition diagnosis. For example, a nutrition diagnosis term of excessive protein intake accompanied by an elevated serum creatinine or blood urea nitrogen level could potentially be addressed with an intervention of an education session linking protein intake to kidney function (NE-E-1.4) (Beto et al., 2014). An intervention typically involves an action or an active change expectation. Some selected nutrition interventions in CKD might include education (e.g., patient-adapted learning materials) or initiation of an intervention (e.g. calorie count, change in timing of meals or medications, ordering a dietary supplement or change in diet prescription) (Brommage et al., 2009; Holli, 2012).

\section{(iv) Monitoring and evaluation}

Patients with CKD stages 3 to $4 / G 3$ to G4 require progressive cycles of monitoring and evaluation activities due to the chronic nature and progressive risk of kidney injury. As with any education strategy to enact change, dieticians need to use a multitude of tools and techniques tailored to the patient's needs and skill level (Beto et al., 2014). When multiple nutrition diagnoses are present, the dietician needs to work with the patient to prioritize them to achieve meaningful sustained results rather than intermittent success (Memmer, 2013; Holli, 2012). The dietician is in a unique position to be a key member of the interdisciplinary team for planning and monitoring. Communication among team members is essential to deliver coordinated care (Brommage et al., 2009). Understanding the role of each component in the nutrition prescription will help connect rationale with application. The priority of each component often changes in conjunction with variables of treatment, medical complications, co morbid conditions, medications, and social/behaviour issues (Beto et al., 2014).

\section{Conclusion}

The NCPM provides a consistent structure and framework for food and nutrition professionals to use when delivering nutrition care. The Nutrition Care Process consists of four distinct, but interrelated and connected steps. Even though each step builds on the previous one, the process is not linear. The Nutrition Care Process cycles through the steps of assessment, diagnosis, intervention, and monitoring and evaluation. Nutrition care can involve one or more cycles and ends, ideally, when nutrition goals have been achieved. Activities of registered dieticians within the four steps of the Nutrition Care Process are described using the International Dietetics and Nutrition Terminology (IDNT) which is an important aspect of NCP. The online IDNT was launched in 2014 as the eNCPT with updated terminology and improved web platform. Integration of the NCPM and IDNT into computerized medical record systems is beneficial for tracking and monitoring data sets measuring health outcomes as a result of nutrition care. Malnutrition is an important feature of CKD and hence proper nutrition is essential to reduce morbidity and mortality among CKD patients. Implementing Nutrition Care Process provides a framework for demonstrating that nutrition care improves outcomes. Implementation of the NCP helps to generate comparative data and information relating to the impact 
of nutrition interventions to resolve nutrition problems. The implementation of a systematic approach to patient care, in line with nutrition care process may improve dietary intake and nutritional status in CKD patients, without the need for increased resources or dietician time. Providing individualised nutritional counselling may improve many components of quality of life, compared with standard nutrition care.

\section{Conflict of interest statement}

Authors declare that they have no conflict of interest.

\section{References}

ADA, 2007. Nutrition Diagnosis and Intervention: Standardized Language for the Nutrition Care Process. American Dietetic Association, 2007.

ADA, 2011. International Dietetics and Nutrition Terminology (IDNT) Reference Manual: Standardized Language for the Nutrition Care Process. American Dietetic Association, 2011.

Akdag, I., Yilmaz, Y., Kahvecioglu, S., Bolca, N., Ercan, I., Ersoy, A., Gullulu, M., 2008. Clinical value of the malnutrition-inflammation-atherosclerosis syndrome for long-term prediction of cardiovascular mortality in patients with end-stage renal disease: a 5-year prospective study. Nephron Clin. Pract. 108(2), c99-c105.

Anand, M. P., 2000. Prevalence of hypertension amongst Mumbai executives. J. Assoc. Physicians India. 48(12), 1200-1201.

Ash, S., Campbell, K.L., Bogard, J., Millichamp, A., 2014. Nutrition prescription to achieve positive outcomes in chronic kidney disease: A systematic review. Nutrients. 6(1), 416-451.

Atkins, M., Basualdo-Hammond, C., Hotson, B., 2009. Canadian perspectives on the nutrition care process and international dietetics and nutrition terminology Can. J. Diet. Pract. Res. 71(2), e18-20.

Beto, J.A., Ramirez, W.E., Bansal, V.K., 2014. Medical nutrition therapy in adults with chronic kidney disease: Integrating evidence and consensus into practice for the generalist registered dietitian nutritionist. J. Acad. Nutr. Diet. 114(7), 1077-1087.

Bisognano, M., 2000. New skills needed in medical leadership. Quality Progress. 33(6), 32.

Brommage, D., Karalis, M., Martin, C., McCarthy, M., Benner, D., Goeddeke-Merickel, C.M., Wiesen, K., Byham-Gray, L., House, J.L., Pavlinac, J., McCann, L., 2009. American Dietetic Association and the National Kidney Foundation standards of practice and standards of professional performance for registered dietitians (generalist, specialty, and advanced) in nephrology care. J. Renal Nutr. 19(5), 345-356.

Caglar, K., Hakim, R.M., Ikizler, T.A., 2002. Approaches to the reversal of malnutrition, inflammation, and atherosclerosis in end-stage renal disease. Nutr. Rev. 60(11), 378-387.

Campbell, K. L., Ash, S., Bauer, J. D., 2008. The impact of nutrition intervention on quality of life in pre-dialysis chronic kidney disease patients. Clin. Nutr. 27(4), 537544.

Campbell, K. L., Ash, S., Zabel, R., McFarlane, C., Juffs, P., Bauer, J. D., 2009. Implementation of standardized nutrition guidelines by renal dietitians is associated with improved nutrition status. J. Renal Nutr. 19(2), 136-144.

Carpenito Moyet, L.J. (Ed.), 2006. Nursing Diagnosis: Application to Clinical Practice. Lippincott Williams \& Wilkins.

Chadban, S. J., Briganti, E. M., Kerr, P. G., Dunstan, D. W., Welborn, T. A., Zimmet, P. Z., Atkins, R. C., 2003. Prevalence of kidney damage in Australian adults: The AusDiab kidney study. J. Am. Soc. Nephrol. 14(Suppl 2), S131-S138.

Charney, P., 2006. The nutrition care process and standardized language of dietetics: implications for the nutrition support dietitian. Support Line. 28(2), 16.

Chauveau, P., Combe, C., Laville, M., Fouque, D., Azar, R., Cano, N., Canaud, B., Roth, H., Leverve, X., Aparicio, M., French Study Group for Nutrition in Dialysis, 2001. Factors influencing survival in hemodialysis patients aged older than 75 years: 2.5-year outcome study. Am. J. Kidney Dis. 37(5), 997-1003.

Coresh, J., Selvin, E., Stevens, L.A., Manzi, J., Kusek, J.W., Eggers, P., Van Lente, F., Levey, A.S., 2007. Prevalence of chronic kidney disease in the United States. JAMA, 298(17), 2038-2047.

Doenges, M. E., Moorhouse, M. F., 2012. Application of Nursing Process and Nursing Diagnosis: An Interactive Text for Diagnostic Reasoning. F. A. Davis Company, PA.

Donaldson, N. E., Rutledge, D. N., Ashley, J., 2004. Outcomes of adoption: measuring evidence uptake by individuals and organizations. Worldviews Evid. Based Nurs. 1 (Suppl. 1), S41-S52.

Eck, L. H., Slawson, D. L., Williams, R., Smith, K., HarmonClayton, K., Oliver, D., 1998. A model for making outcomes research standard practice in clinical dietetics. J. Am. Diet. Assoc. 98(4), 451-457.

Fein PA, Mittman N, Gadh R, 2003. Malnutrition and inflammation in peritoneal dialysis patients. Kidney Int; 64:S87 91.

Fouque, D., Kalantar-Zadeh, K., Kopple, J., Cano, N., Chauveau, P., Cuppari, L., Franch, H., Guarnieri, G., Ikizler, T.A., Kaysen, G. and Lindholm, B., 2008. A proposed nomenclature and diagnostic criteria for proteinenergy wasting in acute and chronic kidney disease. Kidney international, 73(4), pp.391-398.

Fung, F., Sherrard, D.J., Gillen, D.L., Wong, C., Kestenbaum, B., Seliger, S., Ball, A. and Stehman-Breen, C., 2002. Increased risk for cardiovascular mortality among malnourished end-stage renal disease patients. American journal of kidney diseases, 40(2), pp.307-314. 
Gates, G., 2003. Ethics opinion: Dietetics professionals are ethically obligated to maintain personal competence in practice. Journal of the Academy of Nutrition and Dietetics, 103(5), p.633.

Goraya, N. and Wesson, D.E., 2012. Dietary management of chronic kidney disease: protein restriction and beyond. Current opinion in nephrology and hypertension, 21(6), pp.635-640.

Gupta, R., 2004. Trends in hypertension epidemiology in India. Journal of human hypertension, 18(2), pp.73-78.

Hakim, R.M. and Levin, N., 1993. Malnutrition in hemodialysis patients. American journal of kidney diseases, 21(2), pp.125-137.

Holli, B., 2012. Nutrition Counseling and Education Skills for Dietetics Professionals. Lippincott Williams \& Wilkins.

Houston, T.P., Elster, A.B., Davis, R.M. and Deitchman, S.D., 1998. The US Preventive Services Task Force Guide to Clinical Preventive Services, AMA Council on Scientific Affairs. American journal of preventive medicine, 14(4), pp.374-376.

Hsu, C.C., Hwang, S.J., Wen, C.P., Chang, H.Y., Chen, T., Shiu, R.S., Horng, S.S., Chang, Y.K. and Yang, W.C., 2006. High prevalence and low awareness of CKD in Taiwan: a study on the relationship between serum creatinine and awareness from a nationally representative survey. American journal of kidney diseases, 48(5), pp.727-738.

Ibrahim, Z., 2010. Standardised nutrition diagnosis terminology: implications for dietetics practice NOVA. The University of Newcastle's Digital Repository.

Ikizler, T.A., 2004. Role of nutrition for cardiovascular risk reduction in chronic kidney disease patients. Advances in chronic kidney disease, 11(2), pp.162-171.

Ikizler, T.A., Cano, N.J., Franch, H., Fouque, D., Himmelfarb, J., Kalantar-Zadeh, K., Kuhlmann, M.K., Stenvinkel, P., TerWee, P., Teta, D. and Wang, A.Y.M., 2013. Prevention and treatment of protein energy wasting in chronic kidney disease patients: a consensus statement by the International Society of Renal Nutrition and Metabolism. Kidney international, 84(6), pp.1096-1107.

Imai E, Horio M, Watanabe T, Iseki K, Yamagata K, Hara S, Ura N, Kiyohara Y, Moriyama T, Ando Y, Fujimoto S, Konta T, Yokoyama H, Makino H, Hishida A, Matsuo S. 2007. Prevalence of chronic kidney disease (CKD) in the Japanese general population predicted by the MDRD equation modified by a Japanese coefficient. Clin Exp Nephrol, 11(2):156-63.

Kalantar-Zadeh, K., Supasyndh, O., Lehn, R.S., McAllister, C.J. and Kopple, J.D., 2003. Normalized protein nitrogen appearance is correlated with hospitalization and mortality in hemodialysis patients with $\mathrm{Kt} / \mathrm{V}$ greater than 1.20 . Journal of renal nutrition, 13(1), pp.15-25.

Kher, V., 2002. End-stage renal disease in developing countries. Kidney international, 62(1), pp.350-362.

Kobayashi, I., Ishimura, E., Kato, Y., Okuno, S., Yamamoto, T., Yamakawa, T., Mori, K., Inaba, M. and Nishizawa, Y., 2010. Geriatric Nutritional Risk Index, a simplified nutritional screening index, is a significant predictor of mortality in chronic dialysis patients. Nephrology Dialysis Transplantation, p.gfq211.

Kopple, J.D., 1994. Effect of nutrition on morbidity and mortality in maintenance dialysis patients. American journal of kidney diseases, 24(6), pp.1002-1009.

Kopple, J.D., Berg, R., Houser, H., Steinman, T.I. and Teschan, P., 1989. Nutritional status of patients with different levels of chronic renal insufficiency. Kidney International Supplement, (27).

Kopple, J.D., Greene, T., Chumlea, W.C., Hollinger, D., Maroni, B.J., Merrill, D., Scherch, L.K., Schulman, G., Wang, S.R., Zimmer, G.S. and Modification of Diet in Renal Disease Study Group, 2000. Relationship between nutritional status and the glomerular filtration rate: results from the MDRD study. Kidney international, 57(4), pp.1688-1703.

Lacey, K. and Cross, N., 2002. A problem-based nutrition care model that is diagnostic driven and allows for monitoring and managing outcomes. Journal of the American Dietetic Association, 102(4), pp.578-589.

Lacey, K. and Pritchett, E., 2003. Nutrition care process and model: ADA adopts road map to quality care and outcomes management. Journal of the American Dietetic Association, 103(8), pp.1061-1072.

Lii, Y.C., Tsay, S.L. and Wang, T.J., 2007. Group intervention to improve quality of life in haemodialysis patients. Journal of clinical nursing, 16(11c), pp.268-275.

Ma, E.P.M., Worrall, L. and Threats, T.T., 2007. The international classification of functioning, disability and health (ICF) in clinical practice. In Seminars in speech and language (Vol. 28, No. 4, pp. 241-243). Thieme.

Manore, M.M. and Myers, E.F., 2003. Research and the dietetics profession: Making a bigger impact. Journal of the Academy of Nutrition and Dietetics, 103(1), p.108.

Marcén, R., Teruel, J.L., de la Cal, M.A. and Gàmez, C., 1997. The impact of malnutrition in morbidity and mortality in stable haemodialysis patients. Spanish Cooperative Study of Nutrition in Hemodialysis. Nephrology Dialysis Transplantation, 12(11), pp.2324-2331.

Memmer, D., 2013. Implementation and practical application of the nutrition care process in the dialysis unit. Journal of Renal Nutrition, 23(1), pp.65-73.

Modi, G.K. and Jha, V., 2006. The incidence of end-stage renal disease in India: a population-based study. Kidney international, 70(12), pp.2131-2133.

Myers E. 2008. Nutrition Care Process and Model Part I. The 2008 Update. Journal of the American Dietetic Association, 108:1113-1117.

Myers, F., 2008. Nutrition Care Process Part II: Using the International Dietetics and Nutrition terminology to document the nutrition care process. Journal of the American Dietetic Association, 108(8).

O'malley, K.J., Cook, K.F., Price, M.D., Wildes, K.R., Hurdle, J.F. and Ashton, C.M., 2005. Measuring diagnoses: ICD code accuracy. Health services research, 40(5p2), pp.1620-1639. 
Pifer, T.B., Mccullough, K.P., Port, F.K., Goodkin, D.A., Maroni, B.J., Held, P.J. and Young, E.W., 2002. Mortality risk in hemodialysis patients and changes in nutritional indicators: DOPPS. Kidney international, 62(6), pp.22382245.

Ruggenenti, P., Schieppati, A. and Remuzzi, G., 2001. Progression, remission, regression of chronic renal diseases. The Lancet, 357(9268), pp.1601-1608.

Ruperto, M., Sánchez-Muniz, F.J. and Barril, G., 2014. A clinical approach to the nutritional care process in proteinenergy wasting hemodialysis patients. Nutr Hosp, 29(4), pp.735-50.

Sandrick, K., 2002. Is nutritional diagnosing a critical step in the nutrition care process?. Journal of the Academy of Nutrition and Dietetics, 102(3), p.427.

Shojania KG, Duncan BW, McDonald KM, Wachter RM. Making Health Care Safer: A Critical Analysis of Patient Safety Practices. Evidence Report/ Technology Assessment No. 43 (Prepared by the University of California at San Francisco-Stanford Evidence-based Practice Centre under Contract No. 290-97-0013). Rockville, MD: Agency for Healthcare Research and Quality; 2001. Report No.: AHRQ Publication No. 01E058.

Singh, A.K., Farag, Y.M., Mittal, B.V., Subramanian, K.K., Reddy, S.R.K., Acharya, V.N., Almeida, A.F., Channakeshavamurthy, A., Ballal, H.S., Gaccione, P. and Issacs, R., 2013. Epidemiology and risk factors of chronic kidney disease in India-results from the SEEK (Screening and Early Evaluation of Kidney Disease) study. BMC nephrology, 14(1), p.1.

Smith, R., 2003. Expanding medical nutrition therapy: An argument for evidence-based practices. Journal of the American Dietetic Association, 103(3), pp.313-314.

Splett, P. and Myers, E.F., 2001. A proposed model for effective nutrition care. Journal of the Academy of Nutrition and Dietetics, 101(3), p.357.
Splett, P.L., 2000. Developing and validating evidence-based guides for practice: a tool kit for dietetics professionals. American Dietetic Association.

Steiner, W.A., Ryser, L., Huber, E., Uebelhart, D., Aeschlimann, A. and Stucki, G., 2002. Use of the ICF model as a clinical problem-solving tool in physical therapy and rehabilitation medicine. Physical therapy, 82(11), pp.1098-1107.

Stevens, P.E., O'donoghue, D.J., De Lusignan, S., Van Vlymen, J., Klebe, B., Middleton, R., Hague, N., New, J. and Farmer, C.K.T., 2007. Chronic kidney disease management in the United Kingdom: NEOERICA project results. Kidney international, 72(1), pp.92-99.

Underbakke, G.L., 2006. Nutrition Diagnosis: A Critical Step in the Nutrition Care Process. Medicine \& Science in Sports \& Exercise, 38(8), p.1537.29.

White, C.A., Pilkey, R.M., Lam, M. and Holland, D.C., 2002. Pre-dialysis clinic attendance improves quality of life among hemodialysis patients. BMC nephrology, 3(1), p.1.

Wild, S., Roglic, G., Green, A., Sicree, R. and King, H., 2004. Global prevalence of diabetes estimates for the year 2000 and projections for 2030. Diabetes care, 27(5), pp.10471053.

World Health Organization, 2012. Preventing chronic diseases: a vital investment. Geneva: WHO, 2005. Revista Baiana de Saúde Pública.

Yilmaz, M.I., Carrero, J.J., Axelsson, J., Lindholm, B. and Stenvinkel, P., 2007. Low-grade inflammation in chronic kidney disease patients before the start of renal replacement therapy: sources and consequences. Clin. Nephrol. 68(1), 1-9.

Youngstrom, M.J., 2002. The occupational therapy practice framework: The evolution of our professional language. Am. J. Occup. Ther. 56(6), 607-608.

Zyga, S., Christopoulou, G., Malliarou, M., 2011. Malnutrition-inflammation-atherosclerosis syndrome in patients with end-stage renal disease. J. Renal Care. 37(1), 12-15.

\section{How to cite this article:}

Mishra, S. K., Singh, K., Gupta, R. K., 2016. Nutrition care process and chronic kidney disease: A review. Int. J. Curr. Res. Biosci. Plant Biol. 3(6), 129-138. doi: http://dx.doi.org/10.20546/ijcrbp.2016.306.016 